\title{
Dry matter and area partitioning, radiation interception and radiation-use efficiency in open-field bell pepper
}

\author{
M.I. Vieira $^{\mathrm{a}, *}$, J.P. de Melo-Abreu ${ }^{\mathrm{b}}$, M.E. Ferreira ${ }^{\mathrm{a}}$, A.A. Monteiro ${ }^{\mathrm{b}}$ \\ a L-INIA, Oeiras, Av. da República s/n, Nova Oeiras, 2784-505 Oeiras, Portugal \\ ${ }^{\mathrm{b}}$ Instituto Superior de Agronomia, Technical University of Lisbon (TULisbon), Tapada da Ajuda, 1349-017 Lisboa, Portugal
}

\section{A R T I C L E I N F O}

\section{Article history:}

Received 27 June 2008

Received in revised form 4 January 2009

Accepted 4 March 2009

\section{Keywords:}

Capsicum annuum L.

Dry matter distribution

Specific leaf area

Extinction of radiation

Light-use efficiency

Photosynthetic efficiency

Model

\begin{abstract}
A B S T R A C T
The objective of this study was to determine some key components of a model for bell pepper growth and yield under non-limiting water and nutrient conditions using data from field trials conducted in Southern Portugal. DM partitioning, at least before fruiting, and specific area indices for leaves, stems and fruits were conservative in relation to normalized thermal time. The interception model had a good performance. It was based on the exponential extinction of radiation on the area covered by the plants, the ellipsoidal leaf-angle distribution model ( $X$-parameter 2.48 and 2.89), and absorptivities of the leaves for PAR and NIR, 0.8 and 0.2, respectively. Radiation-use efficiency (RUE) was determined and presented in four different forms. RUE did not change substantially throughout the growing season. RUE of irrigated pepper crops grown in our experiments was around $1.6 \mathrm{~g} \mathrm{MJ}^{-1}$ of intercepted PAR. The models and parameter values presented in this study may be useful to simulate the development and growth of fieldgrown pepper crop.
\end{abstract}

(c) 2009 Published by Elsevier B.V.

\section{Introduction}

Bell peppers occupy 1.7 million hectares worldwide and produce 26.1 million tonnes of fresh fruit (FAOSTAT, 2007). The cultivated area in Southern Europe and North America is 111000 ha (FAOSTAT, 2007) and the ecological conditions are similar to those of Portugal. Portuguese growers plant about 40000 plants per hectare in paired lines, and the soil is mulched with black PE for weed control, lower soil-water evaporation and higher soil temperature. In general, plants grow without water and nutrient limitations due to the use of drip irrigation and fertigation. Fruit harvest is manual and done in three to five times.

Many crop simulation models (Spitters and Schapendonk, 1990; Stockle and Nelson, 1994; Mariscal et al., 2000; Tubiello and Ewert, 2002) calculate potential crop growth rate as the product of incident radiation by the fraction of intercepted radiation and radiation-use efficiency (RUE) (Monteith, 1977). The fraction of intercepted radiation is calculated from leaf area index (LAI), zenith angle of the radiation, and leaf-angle distribution (see Section 2) (Goudriaan, 1977; Ross, 1981). In order to simulate LAI, most models keep track of the dry matter (DM) present in the

\footnotetext{
* Corresponding author. Tel.: +351 214429824; fax: +351 214411797.

E-mail addresses: misabelvieira@net.sapo.pt (M.I. Vieira),

Melo-Abreu@netcabo.pt, demeloeabreu@gmail.com (J.P. de Melo-Abreu).
}

leaves, and compute LAI as the product of DM and specific leaf area (SLA) (van Keulen et al., 1982; Penning de Vries et al., 1989; Stockle and Nelson, 1994).

The fraction of DM allocated to the different plant parts may often be determined by a fix partitioning approach, especially before grain or fruit growth, if the crop is not subjected to severe stress. Otherwise, partition must be governed by water and nutrient availability through source-sink relationships (Penning de Vries et al., 1989; Stockle and Nelson, 1994; Marcelis et al., 1998, 2006; Vieira et al., 2004).

Simulation approaches used for continuous canopies, with leaves randomly distributed in space, are no longer applicable for discontinuous canopies, such as the canopies of pepper crops. In this case, even the more practical models that minimize the inputs on canopy structure and rely mostly on the geometry of its imaginary outer envelope and assume some kind of extinction law within it are rather complex (Norman and Welles, 1983).

Marcelis et al. (2006) constructed a model for the simulation of bell pepper grown in glasshouses calibrated and validated with data from six crops grown in rockwool in Vento type glasshouses located in The Netherlands and France. Interception of radiation is calculated for a multi-layered uniform canopy, thus not accounting for the fact that, at least for the most part of the crop cycle, the canopy is clearly discontinuous. Also, area expansion is predicted by a model that only considers the temperature sum from planting. Under open-field conditions, varieties, plant growth rate, DM 
partitioning and other plant responses are different and the modelling approaches and parameters need to reflect those conditions.

The objective of this study with field-grown bell peppers, grown without water and nutrient limitations, was to determine important parameters in the interception of radiation, RUE, the courses of DM partitioning and specific areas in relation to normalized thermal time, thus providing key components for pepper simulation models designed to open-field growing conditions. The approach used for the simulation of interception of radiation accounts for the fact that sweet-pepper canopies are discontinuous.

\section{Materials and methods}

Field trials with bell pepper (Capsicum annuum L. cv. Capistrano) were conducted in Southern Portugal (latitude: $37^{\circ} 30^{\prime} \mathrm{N}$, longitude: $8^{\circ} 45^{\prime} \mathrm{W}$, altitude: $106 \mathrm{~m}$ above M.S.L.), in 2000-2002 with three planting dates per year (second fortnight of April and first and second fortnights of May).

The soil was a Podzol (FAO, 1988) with organic matter at $0.70 \%$ and $\mathrm{pH}\left(\mathrm{H}_{2} \mathrm{O}\right)$ 5.9-6.1. Commercially accepted growing techniques and pest management practices were adopted. Six-week-old plants were planted in paired rows $0.40 \mathrm{~m}$ apart, with $0.35 \mathrm{~m}$ distance in the row and $1.5 \mathrm{~m}$ distance between paired-row centres corresponding to a plant density of 3.8 plants $\mathrm{m}^{-2}$. The crop was drip irrigated to maintain available soil water between $60 \%$ and $80 \%$ in the $0-0.3 \mathrm{~m}$ superficial layer and soil water was weekly monitored using the TDR technique (Topp, 1987).

Soil was fertilised in order to provide non-limiting nutrient conditions for the crop. Fertiliser was broadcast and incorporated with a disc harrow, based on the $\mathrm{N}, \mathrm{P}, \mathrm{K}$ and $\mathrm{Mg}$ rates of 60,105 , 365 , and $48 \mathrm{~kg} \mathrm{ha}^{-1}$, respectively. During the growth period, an additional $200 \mathrm{~kg} \mathrm{~N}, 25 \mathrm{~kg} \mathrm{P}, 230 \mathrm{~kg} \mathrm{~K}, 95 \mathrm{~kg} \mathrm{Mg}$, and $30 \mathrm{~kg} \mathrm{Ca} \mathrm{ha}{ }^{-1}$, were conveyed by irrigation water.

Air temperature, relative humidity, total solar radiation, PAR, and wind speed were hourly collected at an automatic weather station (Delta-T Devices, Cambridge, UK) located within the experimental site. Fractional transmission of total solar radiation was determined by one tube solarimeter (Delta-T Devices, Cambridge, UK) placed below the plants in each plot, corresponding to each planting date, and one tube solarimeter placed $1.2 \mathrm{~m}$ above the ground. One inverted quantum sensor (Delta-T Devices, Cambridge, UK) was placed $0.5 \mathrm{~m}$ above the plants to measure reflected PAR.

Data yielded by the experiment were separated randomly into a calibration dataset with data from 2000 and 2001, and in a validation dataset with data from 2002 . When there was no model evaluation involved, but merely a calculation, all data were included such as in the case of RUE calculation.

Model predictions and observations were compared using (1) the statistics of the linear regression analysis of predicted versus observed values (intercept, slope, coefficient of determination); (2) the root mean square error (RMSE) of the estimates and (3) the modelling efficiency, ME (Loague and Green, 1991; Janssen and Heuberger, 1995; Vanclay and Skovsgaard, 1997). ME is a statistic, analogous to the coefficient of determination, that provides an index of performance on a relative scale, where 1 indicates a 'perfect' fit, 0 means that the model is no better than a simple average, and negative values indicate a really poor model. In the case of an evident high performance of the model some of these statistics were not reported.

\subsection{Phenology, dry matter accumulation and leaf area}

Dates of FBN ( $50 \%$ of the plants at the first brunching node), first flower (FF) (50\% of the plants with the first flower opened), first fruit set (FFS) (50\% of the plants with first fruit set) and beginning of maturity (BM) (50\% of the plants with first ripe fruit) were recorded. On average, 47 days elapsed from planting to first flower and 37 days from first flower to beginning of maturity.

Plants were sampled every two weeks for determining DM partition among above-ground plant parts and other biometric measurements. The samples were oven-dried for $48 \mathrm{~h}$ at $65^{\circ} \mathrm{C}$. The first harvest was carried out when the diameter of the first fruit exceeded $8 \mathrm{~cm}$ (green fruits). The second and third harvests consisted of red fruits. Fruit number, fresh and dry mass were registered for each harvest. Leaf and stem one-sided area was measured at the time of each sampling on two plants per plot, using a leaf area meter (MK2, Delta-T Devices, Cambridge, UK). Fruit area was the product of mean fruit width by mean fruit length. At the time of the samplings, the radius of the circular area occupied by the plants was measured, before they touch each other, and the area covered by the crop was measured thereafter (Vieira, 2006).

The course of DM accumulation and partitioning, course of specific areas, and leaf area indices were expressed in relation to normalized thermal time (NTT). NTT was calculated as the ratio of thermal time elapsed from the time of planting to a given day divided by the thermal time from planting to first flowering. Thermal time accumulation was reduced for high temperatures (above $21^{\circ} \mathrm{C}$ ), and base temperature for thermal time calculations was $7{ }^{\circ} \mathrm{C}$. Bell pepper thermal time from planting to first flowering is $521{ }^{\circ} \mathrm{C}$ days (Ferreira et al., 1997; Vieira et al., 2004).

\subsection{Interception model}

The model used estimates intercepted solar radiation and intercepted PAR from total solar radiation data, LAI (averaged over the area covered by the plants) and leaf-angle distribution.

The fraction of beam radiation transmitted through the canopy, $\tau_{\mathrm{b}}(\psi)$, is

$\tau_{\mathrm{b}}(\psi)=\exp \left[-\sqrt{\alpha} K_{\mathrm{e}}(\psi) L\right]$

where the square root of the absorptivity $(\alpha)$ of the leaves is a correction applied to the extinction coefficient of black leaves $\left(K_{\mathrm{e}}(\psi)\right)$ to account for scattering (Goudriaan, 1977; Ross, 1981); $\psi$ is solar zenith angle, and $L$ is the leaf area index in relation to the area covered by the plants. $L$ is calculated using an empirical relation between leaf area of an individual plant and the area covered by that plant and geometrical considerations (Vieira, 2006). In this study, absorptivity was set to 0.8 and 0.2 for PAR and near infra-red (NIR) wavebands, respectively. In the case of the interception of solar radiation, the interception of PAR and NIR was computed separately and later added (Campbell and Norman, 1998).

The extinction coefficient of black leaves, $K_{\mathrm{e}}(\psi)$, is a function of the zenith angle and leaf-angle distribution and is best calculated according to the ellipsoidal leaf-angle distribution model (Campbell, 1986):

$K_{\mathrm{e}}(\psi)=\frac{\sqrt{X^{2}+\tan ^{2} \psi}}{X+1.774(X+1.182)^{-0.733}}$

where parameter $X$ is the ratio of the horizontal radius and the vertical radius of the ellipsoid.

Diffuse radiation comes from all directions. If an uniform distribution of diffuse radiation in the sky hemisphere is assumed, the diffuse transmission is (Ross, 1981):

$\tau_{\mathrm{d}}=2 \int_{0}^{\pi / 2} \tau_{\mathrm{b}}(\psi) \sin (\psi) \cos (\psi) d \psi$

where $\tau_{\mathrm{b}}(\psi)$ is given by Eq. (1). 
Total solar radiation (or PAR) is composed by beam (direct) and diffuse radiation, which are independently transmitted through the canopy. It follows that total transmission is

$\tau_{\mathrm{t}}(\psi)=\left(1-F_{\mathrm{d}}\right) \tau_{\mathrm{b}}(\psi)+F_{\mathrm{d}} \tau_{\mathrm{d}}$

where the fractional transmission of total radiation, $\tau_{\mathrm{t}}(\psi)$, is obtained by weighing the fractional transmissions of beam and diffuse radiation - i.e., $\tau_{\mathrm{b}}(\psi)$ and $\tau_{\mathrm{d}}$ - with the fraction of total radiation that is diffuse, $F_{\mathrm{d}}$, and beam $\left(1-F_{\mathrm{d}}\right)$. Since we did not measure direct and diffuse radiation we used the approach presented by Spitters et al. (1986) to separate these radiation fluxes. Finally, the fraction intercepted by the canopy is $1-\tau_{\mathrm{t}}$.

In the calibration process, the 30 -min fractional transmission values of total radiation of the calibration dataset were analysed to estimate the $X$-parameter in Eq. (2). Calculations were performed using Solver, the optimization algorithm included in Microsoft Excel.

Validation of the interception model consisted of performing regression analysis of the model-predicted versus measured dailyintercepted radiation for all days of the validation dataset. Other statistics were also calculated (see above).

\subsection{Radiation-use efficiency}

RUE was estimated in four different equivalent forms: as the slope of the linear regression $(y=a+b x)$ of cumulative shoot DM (or gross $\mathrm{CO}_{2}$ assimilation) versus cumulative intercepted total solar radiation (or PAR). The four forms of RUE were reported to allow their use in different modelling approaches.

Cumulative shoot DM was measured, but gross $\mathrm{CO}_{2}$ assimilation was not and had to be estimated. In order to perform this estimate it was necessary to estimate growth and maintenance respirations, and root DM. Growth and maintenance respirations were calculated using the procedure presented in Penning de Vries (1975) and Penning de Vries and Van Laar (1982), with the options adopted in Penning de Vries et al. (1989). $\mathrm{CO}_{2}$ production factor was given a value of $0.44 \mathrm{~g} \mathrm{CO}_{2} \mathrm{~g}^{-1} \mathrm{DM}$. Maintenance coefficients of leaves, stems, roots and fruits at $25^{\circ} \mathrm{C}$ are $0.030,0.015,0.015$ and $0.010 \mathrm{~g} \mathrm{CO}_{2} \mathrm{~g}^{-1} \mathrm{DM}$, respectively. The temperature effect is described by a $Q_{10}$ of 2 . Root DM was calculated as a function of shoot DM, using a function obtained by Nielsen and Veierskov (1988).

Intercepted PAR was related to intercepted total solar radiation using the equations presented in Section 2.2 with an extinction coefficient for PAR equal to 1.35 times the measured extinction coefficient for total solar radiation (Green, 1987).

\section{Results and discussion}

\subsection{Crop area formation}

\subsubsection{Dry matter partitioning}

The course of shoot DM was similar in all years (Fig. 1). Shoot DM was lower in 2000 than in 2001 and 2002. Shoot DM at the time of the last harvest, averaged over all crops, was $0.70,0.84$ and $0.85 \mathrm{~kg} \mathrm{~m}^{-2}$ in 2000, 2001 and 2002, respectively. Total DM allocated to fruits followed the same patterns and was also lower in 2000 (data not shown). Fruit DM production, averaged over all crops, was $0.46,0.58$ and $0.53 \mathrm{~kg} \mathrm{~m}^{-2}$ in 2000,2001 and 2002 , respectively.

The fraction of shoot DM allocated to leaves varied from 0.5 at the time of planting to 0.8 at NTT $=0.75$ (i.e., about 10 days before FF) (Fig. 2). From this stage to the last harvest the fraction of DM allocated to leaves decreased to about 0.2. The course of the fraction of shoot DM allocated to stems was obviously inverse

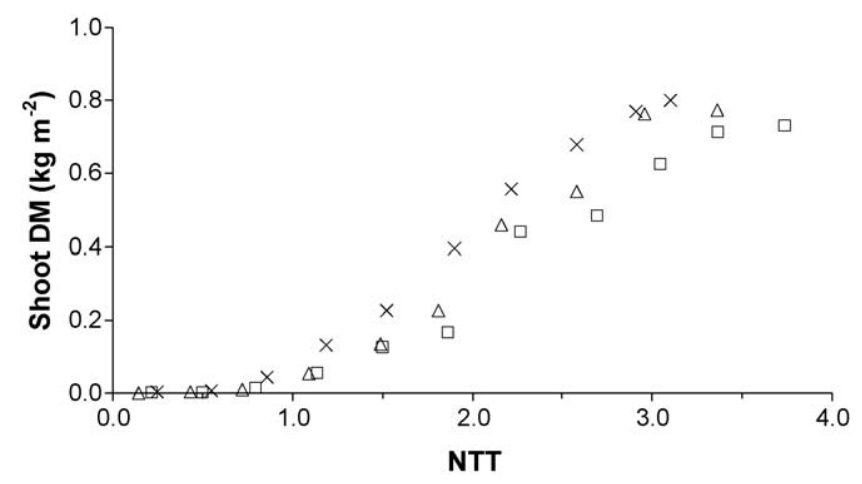

Fig. 1. Shoot DM in relation to normalized thermal time (NTT) for the three years of the experiment $((\square) 2000$; $\triangle(\triangle) 2001 ;(\times) 2002)$. Since all series within a given year were very similar, only the series representing the second sowing date is shown.

before DM allocated to fruits became dominant. After NTT =2, DM allocated to fruits was dominant and continuously increased thereafter (Fig. 2). Before FF, the fractions of above-ground DM allocated to leaves and stems changed with thermal time, but were almost unrelated to the year. Only after the DM allocated to fruits was important, some differences among years were apparent. The justification for these differences is related to the circumstance that fruit growth depends on the number of flowers, the rate of fruit set, and the crop growing conditions. The curves fitted to the fraction of DM in leaves, stems and fruits in the shoot DM and related statistics are presented in Table 1.

In order to simulate DM partitioning, it is usually preferable to separate the fraction of DM or assimilates allocated to the vegetative components of the canopy and to the fruits. Hence, we report separately the fraction of leaves in the above-ground vegetative part of the stand, in relation to NTT. This fraction was fitted with data from the calibration dataset using a piecewise curve. The function fitted to these data was

$F_{\mathrm{L}, \mathrm{V}}= \begin{cases}a+b \theta & \theta \leq 0.80 \\ \operatorname{cexp}(d / \theta) & \theta>0.80\end{cases}$

where $F_{\mathrm{L}, \mathrm{V}}$ is the fraction of the DM of the vegetative part of the canopy present in the leaves, $a, b, \mathrm{c}$ and $d$ are constants, and $\theta$ is NTT. The constants $a, b, c$ and $d$ obtained by regression were 0.60 , $0.27,0.50$ and 0.36 , respectively. Linear regression analysis of predicted versus observed fractions of leaves, performed upon the validation dataset, yielded $r^{2}=0.82$ and $\mathrm{SE}=0.03$, with 32 data points. These results corroborate the validity of the hypothesis of a fix partitioning model for leaves, under similar growing conditions.

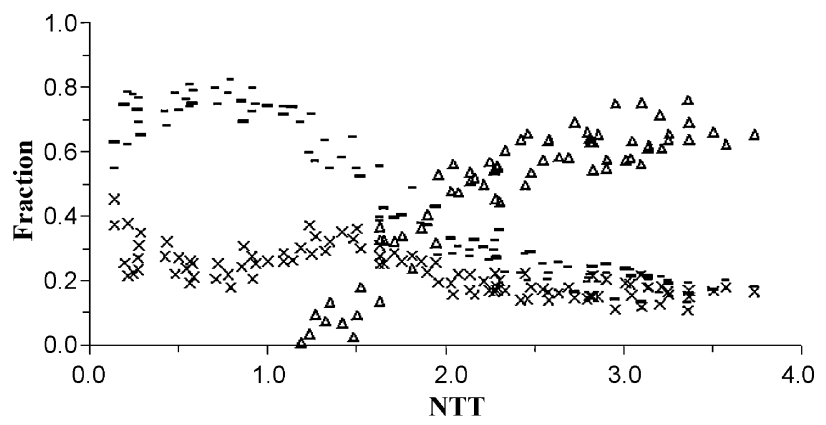

Fig. 2. Fraction of the DM present in leaves $(-)$, stems $(\times)$ and fruits $(\triangle)$ in relation to normalized thermal time (NTT). Values are from the three years of the experiment (2000-2002). 
Table 1

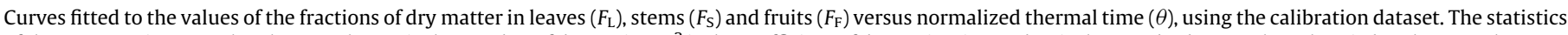

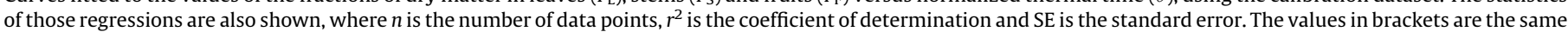
statistics obtained in the linear regression analysis of predicted versus observed values, using the same variables in the validation dataset.

\begin{tabular}{|c|c|c|c|}
\hline Regression equation & $n$ & $r^{2}$ & SE \\
\hline $\begin{array}{l}F_{\mathrm{L}}=0.466+1.11 \theta-1.23 \theta^{2}+0.409 \theta^{3}-0.0445 \theta^{4} \\
F_{\mathrm{S}}=0.544-1.32 \theta+2.01 \theta^{2}-1.28 \theta^{3}+0.347 \theta^{4}-0.0340 \theta^{5}\end{array}$ & $\begin{array}{l}76(32) \\
76(32)\end{array}$ & $\begin{array}{l}0.96(0.98) \\
0.78(0.47)\end{array}$ & $\begin{array}{l}0.04(0.04) \\
0.04(0.05)\end{array}$ \\
\hline$F_{\mathrm{F}}=\frac{4.56 \times 10^{-4}}{6.94 \times 10^{-4}+0.657 \exp (-3.87 \theta)}$ & $49(21)$ & $0.92(0.94)$ & $0.06(0.05)$ \\
\hline
\end{tabular}

\subsubsection{Specific area of leaves, stems and fruits}

The curves fitted to the data of the SLA, specific area of stems (SSA) and fruits (SFA) in relation to NTT showed a diverse course pattern for leaves, stems and fruits (Fig. 3). Before FF, both SLA and SSA decreased abruptly and thereafter SLA oscillated between 12 and $18 \mathrm{~m}^{2} \mathrm{~kg}^{-1}$, while SSA declined from 1.5 to $0.7 \mathrm{~m}^{2} \mathrm{~kg}^{-1}$. For the same NTT the value of SLA is more than one order of magnitude higher than the values of SSA and SFA. The equations and the
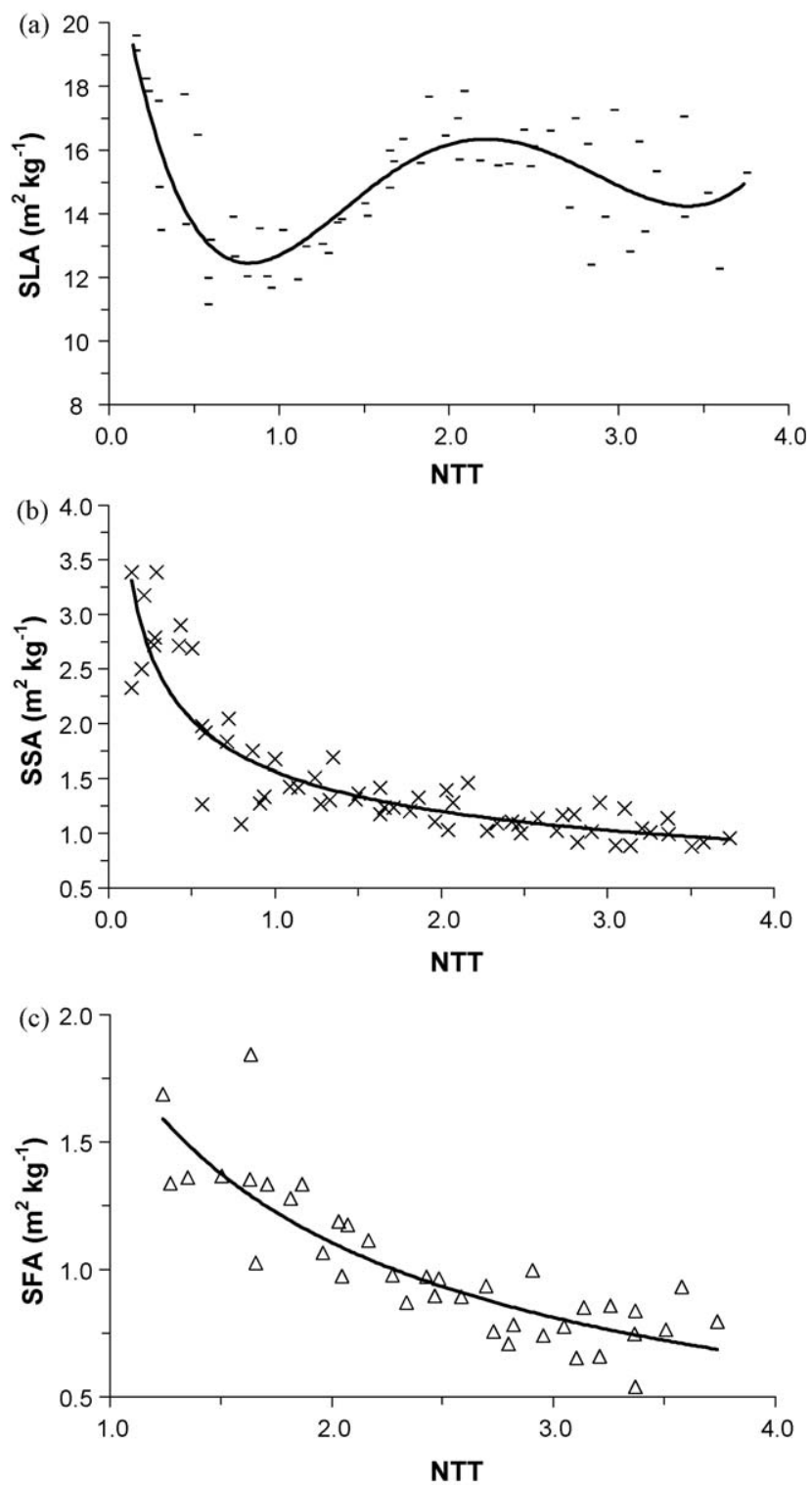

Fig. 3. Specific areas (i.e., areas per unit mass of DM) in relation to normalized thermal time (NTT). (a) Specific leaf area (SLA in $\mathrm{m}^{2} \mathrm{~kg}^{-1}$ ); (b) specific stem area (SSA in $\mathrm{m}^{2} \mathrm{~kg}^{-1}$ ); (c) specific fruit area (SFA in $\mathrm{m}^{2} \mathrm{~kg}^{-1}$ ). Values are from the calibration dataset (2000 and 2001). statistics of these regressions models are shown in Table 2. The same statistics that were obtained in the linear regression analysis of predicted versus observed values, using the validation dataset, are shown in brackets.

Crop area index (CAI) is the sum of the product of the total above-ground DM, the fractions allocated to the different plant parts, and the specific areas, when these variables are all known. Often, leaf area index is calculated, instead of CAI, because the area of stems and fruits is comparatively low. In this case, LAI is the product of leaf DM per unit ground area and specific leaf area. However, detailed models of radiation capture may become more accurate when all contributions are taken into account.

\subsubsection{Area indices}

The course of LAI in relation to NTT, where the area of the leaves was averaged over all the field, was very similar among planting dates within the same crop year (Fig. 4). LAI varied from about $1.5 \mathrm{~m}^{2} \mathrm{~m}^{-2}$ in 2000 to $2.5 \mathrm{~m}^{2} \mathrm{~m}^{-2}$ in 2001 and 2002 , which is as expected. Jolliffe and Gaye (1995) obtained a maximum value of LAI of 2 , but plant density was only 2.8 plants $\mathrm{m}^{-2}$.

Another approach that may be used in crop models consists in using an equation that relates area indices directly to the vegetative above-ground DM (Aase, 1978). In this study, the area index of the vegetative parts (i.e., area of leaves plus stems per unit of ground area) in $\mathrm{m}^{2} \mathrm{~m}^{-2}$ is obtained by the product of 8.96 by the vegetative shoot DM, in $\mathrm{kg} \mathrm{m}^{-2}$. Using the data from all nine crops, in a total of 101 data points, $r^{2}$ was 0.95 and the SE of the estimates was $0.10 \mathrm{~m}^{2} \mathrm{~m}^{-2}$ (data not shown).

In this interception model, LAI averaged over the area covered by the canopy must be calculated daily. Thus, it is necessary to know both the leaf area of the plants and the area covered by these plants. We obtained a regression model relating the area covered by a single plant with the leaf area of that plant, before there is overlap. The regression model relating the area covered by a plant $\left(A_{\mathrm{c}}\right)$ and the area of its leaves $\left(A_{\mathrm{L}}\right)$ is

$A_{\mathrm{c}}=\pi\left(1.33 \sqrt[3]{A_{\mathrm{L}}}+0.64\right)^{2}$

with $r^{2}=0.98$ and $\mathrm{SE}=0.03 \mathrm{~m}^{2}$. Using simple geometric considerations, the area covered by the canopy is calculated (Vieira, 2006).

\section{Table 2}

Curves fitted to the values of specific leaf area (SLA), specific stem area (SSA) and specific fruit area (SFA) versus normalized thermal time $(\theta)$, using the calibration dataset. Specific areas are expressed in $\mathrm{m}^{2} \mathrm{~kg}^{-1}$. The statistics of those regressions are also shown, where $n$ is the number of data points, $r^{2}$ is the coefficient of determination and SE is the standard error $\left(\mathrm{m}^{2} \mathrm{~kg}^{-1}\right)$. The values in brackets are the same statistics obtained in the linear regression analysis of predicted versus observed values, using the same variables in the validation dataset.

\begin{tabular}{llll}
\hline Regression equation & $n$ & $r^{2}$ & SE \\
\hline $\begin{array}{l}\text { SLA }=22.83-30.33 \theta+29.17 \theta^{2} \\
\quad-10.19 \theta^{3}+1.18 \theta^{4}\end{array}$ & $60(32)$ & $0.58(0.50)$ & $1.29(1.08)$ \\
$\mathrm{SSA}=1.56 \theta^{-0.38}$ & $60(32)$ & $0.83(0.92)$ & $0.29(0.14)$ \\
$\mathrm{SFA}=1.88 \theta^{-0.76}$ & $39(18)$ & $0.75(0.83)$ & $0.15(0.09)$ \\
\hline
\end{tabular}




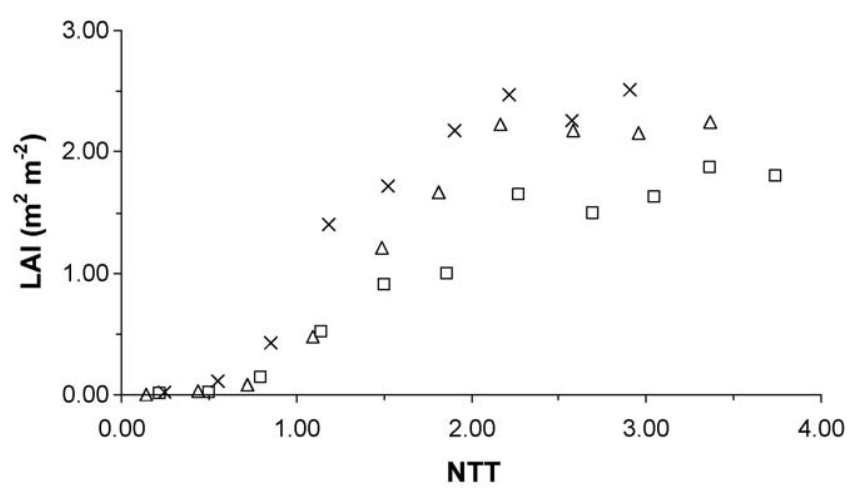

Fig. 4. Leaf area index (LAI) in relation to normalized thermal time (NTT) for the three years of the experiment $((\square) 2000 ;(\triangle)$ 2001; $(\times) 2002)$. Since all series within a given year were very similar, only the series representing the second sowing date is shown.

\subsection{Radiation interception by the crop}

Three short-wave radiation fluxes were measured during crop growth: total solar radiation, reflected solar radiation and transmitted solar radiation. Hence, there were direct measurements of short-wave reflection and transmission coefficients of the canopy, and of the fraction of solar radiation intercepted. From these measurements, it was possible to compute the key parameters to simulate radiation capture by this crop in any waveband, relying on the well established radiative theory (see Section 2).

The ellipsoidal model of leaf-angle distribution (Eq. (2)) is the most useful model to compute the extinction coefficient of any canopy, because it is flexible and uses only one parameter. We inverted this model using the calibration dataset and obtained 2.48 and 2.89 for the values of parameter $X$, before and after NTT 1.5 , respectively.

Using the values of the $X$-parameter obtained in the calibration process, 0.8 and 0.2 for the absorptivities of leaves in the PAR and NIR, respectively, we simulated the total radiation intercepted by the canopies of the crops grown in 2002 (Eqs. (1)-(4)). The plot of simulated versus observed daily values of solar radiation intercepted in the two crops is shown in Fig. 5. The linear regression line was

$y=0.94+0.98 x$

with $r^{2}=0.94$, using 337 data points, and $\mathrm{ME}=0.91$.

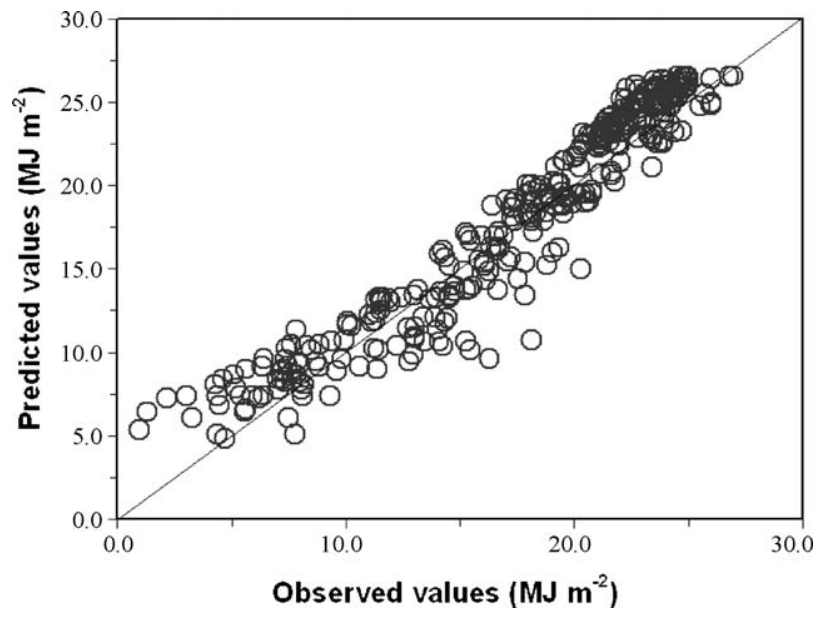

Fig. 5. Predicted versus observed daily-intercepted values of total solar radiation.

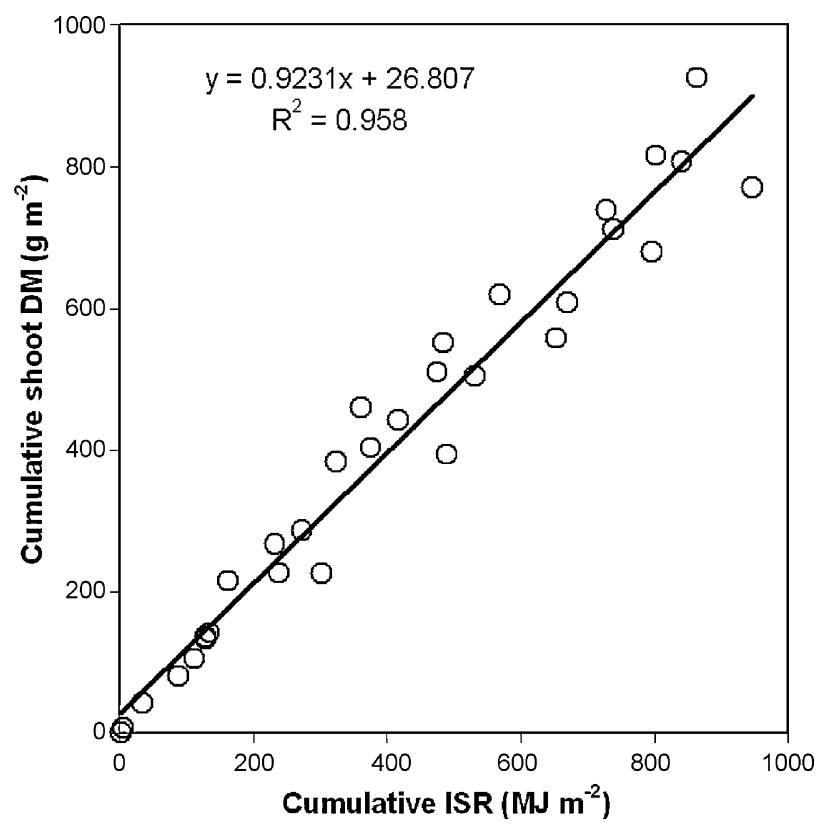

Fig. 6. Linear regression analysis of cumulative shoot $\mathrm{DM}\left(\mathrm{g} \mathrm{m}^{-2}\right)$ versus cumulative intercepted solar radiation $\left(\mathrm{MJ} \mathrm{m}^{-2}\right)$ (ISR). RUE is the slope of the line: $0.9231 \mathrm{~g} \mathrm{MJ}^{-1}$. Values are from the three years of the experiment (2000-2002).

\subsection{Radiation-use efficiency}

RUE was given by the slope of the linear regression of a measure of the cumulative biomass versus a measure of cumulative intercepted radiation. Since the slopes of the regressions were not significantly different between planting dates and years, the RUE was calculated on pooled data over all nine crops. The most common form of RUE, which results from the linear regression of cumulative shoot DM on cumulative total solar radiation (ISR) intercepted by the canopy is shown in Fig. 6. The value of RUE is $0.92 \pm 0.04 \mathrm{~g}(\mathrm{MJ} \text { ISR })^{-1}$. Table 3 shows four different forms of estimates of RUE and related statistics. The first two values result from the relationships between shoot DM and cumulative ISR or intercepted PAR (IPAR), respectively. The last two forms of expressing RUE refer to the relationships between cumulative gross $\mathrm{CO}_{2}$ assimilation $\left(\mathrm{GCA}_{\mathrm{t}}\right)$ and cumulative ISR or cumulative IPAR, respectively. We reported RUE in different forms to allow our results to be used in other models, despite using the most common approach or not. It may be desirable to use gross $\mathrm{CO}_{2}$ assimilation in models that are designed to be sensitive to $\mathrm{CO}_{2}$ elevation, in order to incorporate the response of gross assimilation and maintenance respiration to such conditions. There are no values of RUE available for comparison with those obtained in this study (Table 3), but the values of RUE are within the ranges reported for $C_{3}$ plants of similar species (Russel

Table 3

Linear regression analysis used to calculate radiation-use efficiency (RUE) and related statistics. RUE was estimated as the slope of line $(y=a+b x) . y$ is either cumulative shoot DM $\left(\mathrm{g} \mathrm{m}^{-2}\right)$ or cumulative gross $\mathrm{CO}_{2}$ assimilation, accounting for both above- and below-ground plant parts $\left(\mathrm{GCA}_{\mathrm{t}}\right) ; x$ is either cumulative intercepted solar radiation (ISR) or cumulative intercepted PAR (IPAR); $a$ and $b$ are the intercept and the slope of the line; $r^{2}$ is the coefficient of determination; and $\mathrm{SE}$ is the standard error of the estimates. The number of data points used in each regression was 31 and all regressions were highly significant $(P=0.000)$.

\begin{tabular}{lllllr}
\hline$y\left(\mathrm{~g} \mathrm{~m}^{-2}\right)$ & $x\left(\mathrm{MJ} \mathrm{m}^{-2}\right)$ & $a$ & $b$ & $r^{2}$ & \multicolumn{1}{l}{$\mathrm{SE}$} \\
\hline Shoot DM & ISR & 26.81 & 0.923 & 0.96 & 56.21 \\
Shoot DM & IPAR & 11.75 & 1.612 & 0.94 & 66.10 \\
GCA $_{\mathrm{t}}$ & ISR & 50.18 & 2.469 & 0.96 & 131.7 \\
GCA $_{\mathrm{t}}$ & IPAR & 9.97 & 4.311 & 0.95 & 166.4 \\
\hline
\end{tabular}


et al., 1989; Squire, 1990; Gower et al., 1999). RUE did not change substantially throughout the growing season, in contrast with what is commonly reported for many crops (Squire, 1990; Gower et al., 1999). The absence of noticeable changes in RUE may be related to the fact that pepper is an indeterminate crop and shows little or no senescence in the growing season (Campbell et al., 2001).

\section{Conclusions}

The fractions of shoot DM allocated to leaves, stems, and fruits changed continuously from the onset of growth until the last harvest. Nevertheless, under the cropping conditions of the experiments reported in this study, the partition of DM was almost fix for a given NTT before flowering and changed very little thereafter. Specific areas, when plotted in relation to NTT, depicted the same course despite important differences in growing conditions, due to differences in date of planting and year.

A radiation interception model for open-field bell-pepper crops was set, calibrated and validated. The extinction of radiation of both direct and diffuse radiation was simulated in the discontinuous areas occupied by the plants, accounting for leaf-angle distribution and leaf optical properties. The leaf-angle distribution of pepper tends to be horizontal, depicting a $X$-parameter between 2.48 and 2.89. Model performance was very good despite its relative simplicity.

RUE did not change substantially throughout the growing season. RUE of irrigated pepper crops grown in our experiments was around $1.6 \mathrm{~g}(\mathrm{MJ} \text { PAR })^{-1}$ averaged over the whole season.

\section{Acknowledgement}

This research was funded under projects PIDDAC-138 (20012003) and BD 21387/99 from program PRAXIS XXI.

\section{References}

Aase, J.K., 1978. Relationship between leaf area and dry matter in winter wheat. Agron. J. 70, 563-565.

Campbell, C.S., Heilman, J.L., McInnes, K.J., Wilson, L.T., Medley, J.C., Wu, G., Cobos, D.R., 2001. Seasonal variation in radiation use efficiency of irrigated rice. Agric. For. Meteorol. 110, 45-54.

Campbell, G.S., 1986. Extinction coefficients for plant canopies calculated using an ellipsoidal inclination angle distribution. Agric. For. Meteorol. 36, 317-321.

Campbell, G.S., Norman, J.M., 1998. An Introduction to Environmental Biophysics. Springer-Verlag, New York.

FAO, 1988. Soil Map of the World. World Soil Resources Report 60. FAO, Rome FAOSTAT. Http://faostat.fao.org (accessed on 2008-12-22).

Ferreira, M.E., Abreu, J.P., de Melo e, Bianco, V.V., Monteiro, A., 1997. Predicting phasic development of green beans for processing using a model with high temperature reduction of thermal time accumulation. Sci. Hortic. 69, 123-133.

Goudriaan, J., 1977. Crop micrometeorology: a simulation study. Simulation Monographs. Pudoc, Wageningen.

Gower, S.T., Kucharik, C.J., Norman, J.M., 1999. Direct and indirect estimation of lea area index, $f_{A P A R}$ and net primary production of terrestrial ecosystems. Remote Sensing Environ. 70, 29-51.
Green, C.F., 1987. Nitrogen nutrition and wheat growth in relation to absorbed solar radiation. Agric. For. Meteorol. 41, 207-248.

Janssen, P.H.M., Heuberger, P.S.C., 1995. Calibration of process-oriented models. Ecol. Model. 83, 55-66.

Jolliffe, P.A., Gaye, M.M., 1995. Dynamics of growth and yield component responses of bell peppers (Capsicum annuum L.) to row cover and population density. Sci. Hortic. 62, 153-164.

Loague, K., Green, R.E., 1991. Statistical and graphical methods for evaluating solute transport models: overview and application. J. Contam. Hydrol. 7, 51-73.

Marcelis, L.F., Heuvelink, E., Goudriaan, J., 1998. Modelling biomass production and yield of horticultural crops: a review. Sci. Hortic. 74, 83-111.

Marcelis, L.F.M., Elings, A., Bakker, M.J., Brajeul, E., Dieleman, J.A., de Visser, P.H.B., Heuvelink, E., 2006. Modelling dry matter production and partitioning in sweet pepper. Acta Hortic. 718, 121-128.

Mariscal, M.J., Orgaz, F., Villalobos, F.J., 2000. Radiation-use efficiency and dry matter partitioning of a young olive (Olea europaea) orchard. Tree Physiol. 20, 65-72.

Monteith, J.L., 1977. Climate and the efficiency of crop production in Britain. Philos. Trans. R. Soc. Lond. B 281, 277-294.

Nielsen, T.H., Veierskov, B., 1988. Distribution of dry matter in sweet pepper plants (Capsicum annuum L.) during the juvenile and generative growth phases. Sci. Hortic. 35, 179-187.

Norman, J.M., Welles, J.M., 1983. Radiactive transfer in an array of canopies. Agron. J. 75, 481-488.

Penning de Vries, F.W.T., 1975. The cost of maintenance processes in plant cells. Ann. Bot. 39, 77-92.

Penning de Vries, F.W.T., Jansen, D.M., Berge, H.F.M. ten, Bakema, A., 1989. Simulation of ecophysiological processes of growth in several annual crops. Simulation Monographs 29. Pudoc, Wageningen.

Penning de Vries, F.W.T., Van Laar, H.H., 1982. Simulation of growth processes and the model BACROS. In: Penning de Vries, F.W.T., Van Laar, H.H. (Eds.), Simulation of Plant Growth and Crop Production. Pudoc, Wageningen.

Ross, J., 1981. The Radiation Regime and Architecture of Plant Stands. Dr. W. Junk Publishers, The Hague.

Russel, G., Jarvis, P.G., Monteith, J.L., 1989. Absorption of radiation by canopies and stand growth. In: Russel, G., Marshall, B., Jarvis, P.G. (Eds.), Plant Canopies: Their Growth, Form and Function, Cambridge University Press, pp. 21-39.

Spitters, C.J.T., Schapendonk, H.C., 1990. Evaluation of breeding strategies for drought tolerance in potato by means of crop growth simulation. Plant Soil 123, 193-203.

Spitters, C.J.T., Toussaint, H.A.J.M., Goudriaan, J., 1986. Separating the diffuse and direct component of global radiation and its implications or modeling canopy photosynthesis. Part I. Components of incoming radiation. Agric. For. Meteorol. 38, 217-229.

Squire, G.R., 1990. The Physiology of Tropical Crop Production. CAB International, Wallingford, UK.

Stockle, C.O., Nelson, R., 1994. The CropSyst User's Manual. Biological Systems Engineering Department, Washington State University, Pullman, WA, USA.

Topp, G.C., 1987. The application of time-domain reflectometry (TDR) to soil water content measurement. Proceedings of the International Conference on Measurement of Soil and Plant Water Status, vol. 1. UTAH State University, USA.

Tubiello, F.N., Ewert, F., 2002. Simulating the effects of elevated $\mathrm{CO}_{2}$ on crops: approaches and applications for climate change. Eur. J. Agron. 18, 57-74.

van Keulen, H., Penning de Vries, F.W.T., Drees, E.M., 1982. A summary model for crop growth. In: Penning de Vries, F.W.T., Van Laar, H.H. (Eds.), Simulation of Plant Growth and Crop Production. Simulation Monographs. Pudoc, Wageningen.

Vanclay, J.K., Skovsgaard, J.P., 1997. Evaluating forest growth models. Ecol. Model. $98,1-12$.

Vieira, M.I., 2006. Modelo de Simulação do Desenvolvimento, do Crescimento e da Produtividade do Pimento (Capsicum annuum L.) para congelação. Tese de Doutoramento. ISA, Universidade Técnica de Lisboa, Lisboa (in Portuguese).

Vieira, M.I., Ferreira, M.E., de Melo-Abreu, J.P., 2004. Above-ground assimilate partitioning in bell pepper (Capsicum annuum L.) for processing under Mediterranean conditions. Acta Hortic. 654, 221-227. 